\begin{tabular}{ccc}
\hline International Journal of Engineering \& Technology, $7(4.38)(2018) 1310-1313$ \\
SPC \\
Website: www.sciencepubco.com/index.php/IJET \\
Research paper
\end{tabular}

\title{
A Flash Flood Early Warning System for Rural Kenya: A Pilot Study
}

\author{
Prof. Dr. Ir Vinesh Thiruchelvam and Mbau Stella Nyambura* \\ Asia Pacific University of Innovation and Technology, 57000 Kuala Lumpur, Malaysia
}

\begin{abstract}
The cost of climate change has increased phenomenally in recent years. Therefore, understanding climate change and its impacts, that are likely to get worse and worse into the future, gives us the ability to predict scenarios and plan for them. Flash floods, which are a common result of climate change, follow increased precipitation which then increases risk and associated vulnerability due to the unpredictable rainfall patterns. Developing countries suffer grave consequences in the event that weather disasters strike because they have the least adaptive capacity. At the equator where the hot days are hotter and winds carrying rainfall move faster, Kenya's Tana River County is noted for its vulnerability towards flash floods. Additionally, this county and others that are classified as rural areas in Kenya do not receive short term early warnings for floods. This county was therefore selected as the study area for its vulnerability. The aim of the study is therefore to propose a flash flood early warning system framework that delivers short term early warnings. Using questionnaires, information about the existing warning system will be collected and analyzed using SPSS. The results will be used to interpret the relationships between variables of the study, with a particular interest in the moderation effect in order to confirm that the existing system can be modified; that is, if the moderation effect is confirmed.
\end{abstract}

Keywords: Early warnings, Early warning systems, Floods, Resilience, Rural Kenya

\section{Introduction}

Floods are one of the costliest natural disasters experienced around the world as noted.1 Unterberger notes that extreme rainfall events have increased globally by $12 \%$ between 1981 and 2010.2 To adapt to climate change and the related extreme weather events, the Sustainable Development Goals were adopted in September 2015. They emphasize that partaking in sustainability activities should be a global affair.3

Climate change contributors and those that are not, are equally exposed to the associated risks; developed and developing countries alike. However, developing countries are more vulnerable to these risks. 45 In the case of flash floods, the lack of early warnings makes rural Africa particularly vulnerable. This is due to the lack of weather radars in Africa.6 Kenya is found at the equator of Africa and adjacent to the Indian ocean. Kenya's Tana river is $1000 \mathrm{~km}$ long and the longest in East Africa, and drains its waters into the Indian ocean. When it rains in the central highlands of Kenya, the river water causes flooding in the flood plain in Tana River County.

These scenarios exhibit the vulnerability of communities that live in this county making it a good study area for this research.

Another reason for the selection of this county as a study area is the existing infrastructure that carries out early warning delivery functions, the 'Una Uhakika' Project that is now using drones for surveillance and is dubbed the Sentinel project. This is of particular interest to this study because it has been successfully implemented in the county, where there are challenges of internet connectivity.7 Furthermore, because the drones operate in flight mode, they do not pose a threat to the ecological infrastructure existing in the county. Innovatively using the already available infrastructure in Tana River County, could lead to technologies that best suit rural Kenya.8 Furthermore, drones have been applauded as a fast track tool towards development for developing countries; the leap frog effect. This is because they go where infrastructure and roads do not. 9

The problem being studies is the lack of short term early warnings in rural Kenya where communities have the least adaptive capacity.10 This also presents the gap in knowledge that the lack of weather radars in Kenya means the lack of short term early warnings. 6

The study contributes to the climate change resilience theory and discusses the need for such a system to ensure that vulnerable communities are made more resilient. It also contributes to the decision support theory stating that these early warning systems should have the following functions; observation networks, data management, data analysis and dissemination strategies. These are also present in the World Meteorological Organization's benchmark criterion whose role is to ensure that early warning systems are accurate. 11 In this study the independent variable (IV) is flash flood early warning systems (also existing system), the moderator variable (MV) is real time decision support systems (also proposed system), the mediator variable $(\mathrm{MeV})$ is the ancillary elements and the dependent variable (DV) is short term early warnings. 


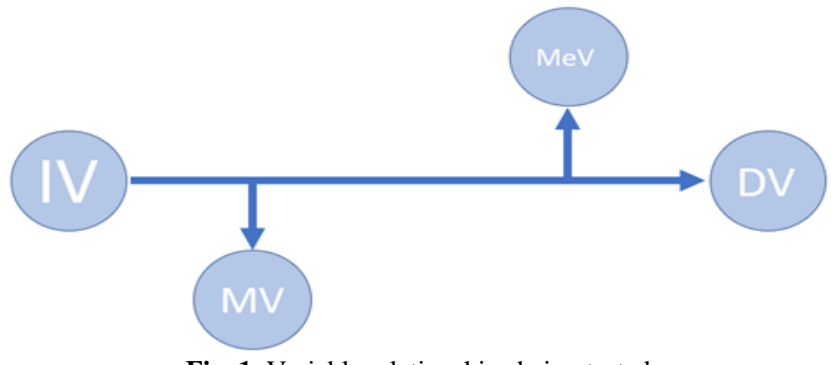

Fig. 1. Variable relationships being tested

The aim of this research is to propose a flash flood early warning system framework that supports a minimum lead time of 30 minutes on short term early warnings. The framework should consider preservation of the ecological infrastructure in Tana River County. The research objective being investigated through this pilot study is: To investigate the moderation effect of real time Decision Support Systems on the existing flash flood early warning systems in rural Africa.

\section{Experimental Details}

This section highlights the pilot study undertaken in this research. The evaluation of the existing flash flood early warning system was undertaken as described below.

\section{Sampling Technique}

The Data Sought For This Research Is Meteorology Specific In Nature Therefore Expert Sampling Will Be Used. Kenyan Respondents Will Be Accessed Through The World Meteorological Organization (Wmo) Expert Database Which Also Gives Access To Individual Emails. 100 Of These Experts Will Be Selected Randomly To Represent The Population And The Aim Will Be To Reach A Sample Size Of 30 Respondents.12 An Assumption That Respondents Have The Relevant Expertise And Knowledge Required Is Made Because They Are Listed By The Wmo Which Further Ensures Internal Validity.

Study Area

Tana River County Is Named After Tana River (Longest River In Kenya) And Has A Population Of 240,075 As Recorded In The 2009 Census. 7

Data Collection

Questionnaires Are Preferred For This Study Because They Are Familiar To Most People. Statements Used Will Be Presented In A Closed Ended Format And Scored On An Ordinal Scale Of 0 To 5 Where: $1=$ Strongly Disagree; $2=$ Disagree; $3=$ Neutral; 4= Agree; $5=$ Strongly Agree. Initially, Pre-Testing Will Be Conducted Via Email To Gather Information From 2 Experts In Kenya In Order To Detect Weaknesses In The Questionnaire Design.13 They Will Receive Word Documents In Which They Can Provide Comments.

\section{Procedures}

SPSS will be used for analysis of primary data gathered. Data will be coded and entered into the tool. Missing values analyses will be performed for all the items in the questionnaire. Internal consistency will be evaluated by determining the Cronbach alpha of at least .7 while correlation between variables will be conducted using Pearson's test. A change in the R2 value of between 0 and 1 will further be used to check whether there is a moderation effect, that is, whether the proposed short term early warning system modifies the relationship between infrastructure elements and short-term early warnings.14 13

\section{Pilot Test Results}

Out of the pool of 100 Kenyan experts, those enlisted and with available email addresses, 28 respondents recorded their answers on the web based questionnaire bringing the response rate to $28 \%$. Data from the questionnaire that contained 55 items was exported as an excel file that was then imported into SPSS for analysis. For the questionnaire in this study a likert scale was used to measure relationships within the variables. Meteorologists were asked to evaluate items on the 5 point bipolar scale where $1=$ strongly disagree, $2=$ disagree, $3=$ neutral, $4=$ agree and $5=$ strongly agree 13 The Cronbach alpha for the questionnaire was .925 and the standardized item alpha was .918 as presented in the table below. These values meet the conventional standards for scale reliability. The 'alpha if item deleted' analysis reported a range of values between .920 and .927 for the items being measured which means the scale is reliable. 15

Table 1: Reliability Statistics

\begin{tabular}{|c|c|c|}
\hline \multicolumn{3}{|c|}{ Table 1: Reliability statistics } \\
\hline $\begin{array}{l}\text { Cronbach's } \\
\text { Alpha }\end{array}$ & $\begin{array}{l}\text { Cronbach's } \\
\text { Alpha Based on } \\
\text { Standardized } \\
\text { Items }\end{array}$ & $\mathrm{N}$ of Items \\
\hline .925 & .918 & 55 \\
\hline
\end{tabular}

To test correlation amongst the variables of this study the Pearson's correlation test was conducted.16 17 For valid results the following assumptions had to be met.

Firstly, the variables had to be continuous and measured on a likert scale. Secondly, scatterplots for each of the variables against the dependent variable, were used to test for linearity.

This test did not yield results that would inform linearity due to the sample size therefore a nonparametric test was sort. This led to running the Spearman correlation test with null hypotheses stating that none of the variables were correlated to the dependent variable. The result after testing the IV and DV was a p value of .703. With this value the null hypothesis was not rejected and therefore the two variables were uncorrelated. Similarly, $\mathrm{p}$ value after testing the MV and DV was .929 and null hypothesis was accepted. However, the $\mathrm{p}$ value after testing the $\mathrm{MeV}$ and DV was <.001 whose statistical significance indicated that the null hypothesis was rejected since the two variables were correlated. Thirdly, to ensure no significant outliers in the data, scatterplots were used once again. However, they did not clearly show the outliers. Finally, a test for normality confirmed that the items were all normally distributed. Having met $50 \%$ of the assumptions, a two-tailed Pearson correlation test was run under the assumption that with a larger sample size $(n>30)$ the other assumptions could also be met.

There was significant evidence of a moderate positive correlation between the IV and MV $(\mathrm{r}=.423, \mathrm{p}=.05)$ and a strong positive correlation between the $\mathrm{MeV}$ and $\mathrm{DV}(\mathrm{r}=.757, \mathrm{p}<.001)$ as shown in the table below. The null hypotheses for the other relationships could not be rejected meaning the variables in question were therefore unrelated. 
Table 2. Correlations

\begin{tabular}{|c|c|c|c|c|c|}
\hline & & IV & MV & $\mathrm{MeV}$ & DV \\
\hline \multirow[t]{3}{*}{ IV } & $\begin{array}{l}\text { Pearson } \\
\text { Correlation }\end{array}$ & 1 & $.423^{*}$ & .301 & .215 \\
\hline & Sig. (2-tailed) & & .025 & .120 & .272 \\
\hline & $\mathrm{N}$ & 28 & 28 & 28 & 28 \\
\hline \multirow[t]{3}{*}{ MV } & $\begin{array}{l}\text { Pearson } \\
\text { Correlation }\end{array}$ & $.423^{*}$ & 1 & .083 & -.009 \\
\hline & Sig. (2-tailed) & .025 & & .673 & .963 \\
\hline & $\mathrm{N}$ & 28 & 28 & 28 & 28 \\
\hline \multirow[t]{3}{*}{$\mathrm{MeV}$} & $\begin{array}{l}\text { Pearson } \\
\text { Correlation }\end{array}$ & .301 & .083 & 1 & $.757^{* *}$ \\
\hline & Sig. (2-tailed) & .120 & .673 & & .000 \\
\hline & $\mathrm{N}$ & 28 & 28 & 28 & 28 \\
\hline \multirow[t]{3}{*}{ DV } & $\begin{array}{l}\text { Pearson } \\
\text { Correlation }\end{array}$ & .215 & -.009 & $.757^{* *}$ & 1 \\
\hline & Sig. (2-tailed) & .272 & .963 & .000 & \\
\hline & $\mathrm{N}$ & 28 & 28 & 28 & 28 \\
\hline
\end{tabular}

A moderation effect was investigated to confirm that the existing system could be modified by a real-time decision support system.18 A multiple regression was applied to investigate whether the association between the existing system (IV) and early warnings (DV) could depend on a real-time decision support system (MV). Firstly, the IV and MV values were standardized. After this an interaction term was computed between the independent and moderator standardized variables. The interaction term when correlated with the DV was statistically significant $(\mathrm{r}=.42, \mathrm{p}=.026)$ compared to the correlation between the IV and DV that showed no correlation. The IV, MV and the interaction term (ZModerator) were then simultaneously run in a regression model.

As shown in the table below, the existing system (IV) reported $\mathrm{b}=.047, \mathrm{SE}=.069, \beta=.137, \mathrm{p}=.501$ and the real-time decision support system (MV) reported $b=-.225, \mathrm{SE}=.142, \beta=-.337, \mathrm{p}=.125$. Interaction of IV and MV labelled ZModerator registered significance at $b=2.126, \mathrm{SE}=.839, \beta=.534, \mathrm{p}<0.05$.

Increase in variation explained by the addition of the interaction term was reported as the change in R2 which was .199 (19.9\% increase). This change was statistically significant at $p<.05$ meaning that the MV in this study could modify the relationship between the IV and DV.

Table 3. Coefficients

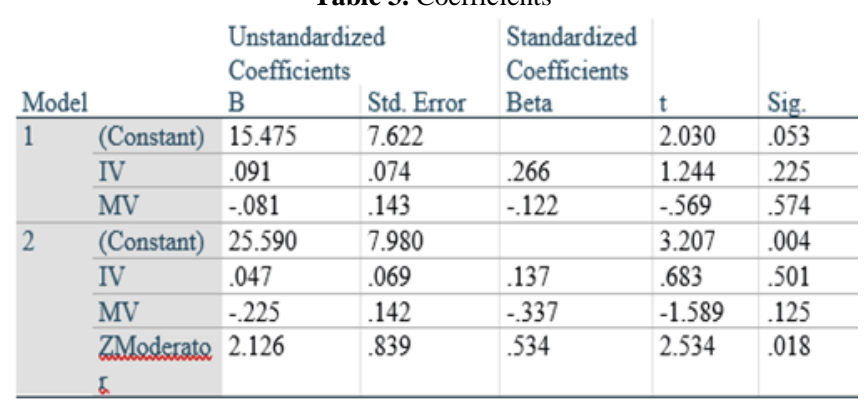

To interpret the direction of the moderation output, a graph was generated using standardized beta values in the following equation:

Standardized values of $\mathrm{DV}=(0.137 \times \mathrm{IV})-(0.337 \times \mathrm{MV})+$ (0.534 x IV x MV)

Using Excel graphs, the equation stated above was estimated when; IV and MV are both +1 ; IV is -1 and MV is +1 ; IV is +1 and MV is -1 ; and finally, when IV and MV are both -1 . These are presented below:

Equation $1 ;(0.137 \times 1)-(0.337 \times 1)+(0.534 \times 1 \times 1)$

... (i)

Answer $=0.334$
Equation $2 ;(0.137 \times-1)-(0.337 \times 1)+(0.534 \times-1 \times 1)$

(ii)

Answer $=-1.008$

Equation $3 ;(0.137 \times 1)-(0.337 \times-1)+(0.534 \times 1 \times-1)$

(iii)

Answer $=0.06$

Equation $4 ;(0.137 \mathrm{x}-1)-(0.337 \mathrm{x}-1)+(0.534 \mathrm{x}-1 \mathrm{x}-1)$

(iv)

Answer $=0.734$

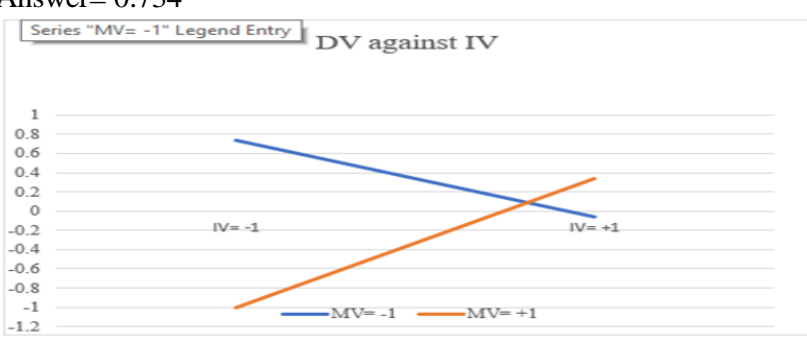

Fig. 2. Interpretation of direction

The graph above shows simple slopes of the interaction between IV and DV at $\mathrm{z}=1$ and $\mathrm{z}=-1$ levels of real time decision support system (MV). When the MV levels are high the relationship between the IV and DV is inversely proportional. However, at the lower levels of the moderator, the relationship between IV and DV is directly proportional.

For the mediation effect a correlation test was run to ensure that all variables in question were correlated. This time however, the ZModerator was correlated to the DV $(r=.42, \mathrm{p}<.05)$ and the ZModerator to the $\mathrm{MeV}(\mathrm{r}=.416, \mathrm{p}<.05)$. The resulting $\mathrm{p}$ values proved correlation. The $\mathrm{MeV}$ and DV were highly correlated at $\mathrm{r}=.757, \mathrm{p}<.05$. Significance level in the IV to DV and IV to MeV relationships were not enough to reject the null hypothesis as established in previous tests, thus, they were noted as uncorrelated. Another regression model between the ZModerator and DV was generated at which the ZModerator reported $\beta=.46 \mathrm{p}<.05$ thus showing correlation. Finally, a multiple regression model was run between the $\mathrm{ZModerator}, \mathrm{MeV}$ and $\mathrm{DV}$ to find $\mathrm{ZModerator}$ $\beta=.128 p<.376$, while the MeV was at $\beta=.703, p<.001$. Mediation was therefore reported because the mediator was found to be statistically significant. Furthermore, the ZModerator was significant in the previous model (ZModerator to DV) but insignificant in the later model that included $\mathrm{MeV}$, which was proof of mediation. 19

\section{Discussions}

The scale used in this study was found to be reliable and therefore the questionnaire will be adopted for the main survey. Results also show that the existing flash flood early warning system is not correlated to early warnings by its own. However, using the interaction term, a product of both the independent and moderator variable, a correlation is established.

The Kenyan experts, whose responses registered normal distribution, were of the opinion that the existing warning system has good performance. However, this did not match the responses for the delivery of short term early warnings. This was attributed to the fact that the system itself is not devolved and therefore its services are not far reaching across Kenya. On the other hand, applying the moderation effect showed that early warnings are associated with the interaction of both the existing system and the proposed system. The mediator, risk knowledge and response capability allude to the fact that, awareness of flash floods and response activities improve the delivery and assimilation of warning information. This variable was reported to be highly correlated 
to early warnings, the dependent variable.

\section{Limitations}

Despite reaching a satisfactory sample size for a pilot study, it is worth noting that there was a long response time. Also, some assumptions required to run statistical tests in this paper were not met. However, the study objective was met, and it is expected that results from a larger sample size should be generalizable.

\section{Conclusions}

This pilot study was conducted in order to check for the appropriateness of methods that would later be used for the main survey. The aim was to investigate the reliability of the data collection tool used as well as the moderation effect between the independent and dependent variables.

The SPSS analysis of data gathered showed that responses were normally distributed for all 28 respondents. Additionally, reliability of the likert scale used in this study was confirmed at $\alpha=.925$. For the relationships between variables, a change in R2 of .199 confirmed moderation effect while mediation was confirmed through the change in significance of the interaction term, ZModerator, after adding the mediator to the regression model. With the objective of the pilot study being met the main survey can now be conducted.

\section{References}

[1] Z. Shilenje, and B. Ogwang, International Journal of Atmospheric Sciences, (2015)

[2] C. Unterberger, Economics of Disasters and Climate Change (2017).

[3] P. R. Jacobi, R. F. Toledo, and E. Grandisoli, Brazilian Journal of Science and Technology (2016).

[4] M. K. Dodo, SpringerPlus (2014)

[5] M. Farnham and P. Kennedy, Environmental and Resource Economics, 61, 3 (2014).

[6] J. Hoedjes, A. Kooiman, B. Maathuis, M. Said, R. Becht, A Limo, M. Mumo, J. N. Mathege, A. Shaka, and B. Su, ISPRS International Journal of Geo-Information, 3, 2 (2014).

[7] C. Tuckwood, and C. Mutisya, Conflict Trends, 3 (2014). Winter, and V. Govindarajan, Havard Business Review (2015). Mungai, World Economic Forum (2015).

[8] S. W. M. Weis, V. N. Agostini, L. M. Roth, B. Gilmer, S. R. Schill, J. E. Knowles, and R. Blyther, Climatic Change, (2016).

[9] Expert Meeting: Improving the Efficiency of Flood Forecasting Services (2013).

[10] G. Johanson, and G. P. Brooks, Educational and Psychological Measurement (2009).

[11] U. Sekaran, and R. Bougie, Research Methods for Business John Wiley and Sons, Inc., West Sussex, United Kingdom, (2016).

[12] C. Kothari, and G. Garg, Research Methodology. New Age International Publishers, Jaipur, India (2014).

[13] K. S. Taber, Research in Science Education (2017)

[14] G. Polančič, G. Jošt, and M. Heričko, Empirical Software Engineering, 20, 1 (2013).

[15] M. Zareen, K. Razzaq, and B. G. Mujtaba, Public Organization Review, 15, 4 (2015).

[16] G. Arslan, Child Indicators Research (2017).

[17] Q. Wang, N. A. Bowling, Q. Tian, G. M. Alarcon, and H. K Kwan, Journal of Business Ethics (2016). 